\title{
International Journal of Medical Sciences

\section{Why are some children with early onset of asthma getting better over the years? - Diagnostic failure or salutogenetic factors}

\author{
Eduardo Roel ${ }^{1}$, Olle Zetterström ${ }^{2}$, Erik Trell ${ }^{1}$, Tomas Faresjö ${ }^{1 凶}$
}

1. Department of Medical and Health Sciences/Community Medicine, Faculty of Health Sciences, Linköping University, SE-581 83 Linköping, Sweden.

2. Department of Clinical and Experimental Medicine / Allergy Centre, Faculty of Health Sciences, Linköping University, SE-581 83 Linköping, Sweden.

Correspondence to: Tomas Faresjö, Assoc Prof., Department of Medical and Health Sciences / Community Medicine, Faculty of Health Sciences, Linköping University, SE-581 83 Linköping, Sweden. Telephone: +46 13222000 ; Fax: +46 13 22 40 20; E-mail: Tomas.Faresjo@liu.se

Received: 2009.07.09; Accepted: 2009.11.17; Published: 2009.11.19

\begin{abstract}
Among children earlier having been identified with a hospital or primary care diagnosis of asthma at least once between 0-7 years of age, almost $40 \%$ of their parents reported in the ISAAC-questionnaire as never having had asthma (NA). These are further analysed and compared with the persisting asthma cases $(\mathbf{A})$ in this study. All these children's medical records were scrutinized concerning their asthma diagnose retrospectively.

The aim of this study was to analyse possible factors related to the outcome in an Asthma diagnosis reassessment by parental questionnaire at the age of ten of the children earlier having been identified with a hospital or primary health care diagnosis of asthma at least once between 0-7 years of age in a total birth-year cohort in a defined Swedish geographical area.

A multiple logistic analysis revealed four significant and independent factors associated to the improvement/non-report of asthma at the age of ten. These factors were; not having any past experiences of allergic symptoms $(p<0.000 \mathrm{I})$, only having one or two visits at the hospital for asthma diagnosis in the $0-7$ interval $(p=0.001)$, not living in a flat but a villa at the age of ten $(p=0.029)$ and no previous perception of mist or mould damage in the house $(p=0.052)$.

In the early postnatal stage, obstructive and bronchospastic symptoms typical of asthma may be unspecific, and those cases not continuing to persisting disease tend to have identifiable salutogenetic factors of constitutional rather than environmental nature, namely, an overall reduced allergic predisposition.
\end{abstract}

Key words: asthma diagnosis, childhood asthma, diagnose setting, follow-up, salutogenetic factors.

\section{Introduction}

In the last decades, the prevalence of childhood asthma has been increasing in many parts of the world, especially in developed countries (1). Particularly in the USA and mainly in urban areas it has almost reached epidemic levels (2), most marked in low-income urban communities (3). Only recently, this global increase of childhood asthma prevalence has shown signs of levelling out or even in some Western countries reversing (4).

Research into the causes of asthma has mostly 
focused on potential risk factors in the environment (5). Childhood asthma is of a multi-factorial nature which indicates that we must have a broader perspective to gain a better understanding of its complex aetiology. In the last years, attention has also been directed towards protective factors. In allergic disorders this research has been focused upon factors that could enhance the development of tolerance to allergens which were previously encountered early in life, but are now disappearing in modern affluent societies (6). However, this so called hygiene hypothesis based on the role of infection in the education of the immune system of young children, can not solely explain the trends in asthma prevalence or account for potential environmental influences on the asthma risks. Asthma could also be seen as a respiratory maladaptation to modern lifestyles and to our increasingly artificial habitats and habits; not the least a progressive decrease of general physical activity $(7,8)$.

Wheeze is common throughout childhood and "transient early wheezing" predominates during the first years of life, although it decreases as children age (9). Studies have shown that abnormalities of neonatal airway function which precede transient wheezing in early childhood do not predict adult obstructive lung disease (10). A longitudinal population-based cohort study has shown that the earlier the age at onset, the greater the chance of relapse (11). So, there is also a chance that some children with wheezing symptoms in early life have outgrown their childhood asthma as teenager or as adults, but asthmatic children who continue to wheeze as adults have poorer baseline spirometry than healthy controls (10). Epidemiological reports have also demonstrated that a certain percentage of subjects with apparently outgrown atopic asthma remain asymptomatic without needing therapy for the rest of their lives, but asthma remission also does exist (12). The more severe the asthma is in childhood the more likely it is that the disease will persist in adulthood and many teenagers who seem to be free of symptoms do, in fact, have persistent asthma (13).

The overall and general target for epidemiological studies is to shed light over potential risk factors for disease (14). More rarely are questions raised of possible factors that might support health or recovery from disease. This alternative research perspective is referred to as a salutogenetic approach to health $(15,16)$. A salutogenetic perspective of childhood asthma could thus be to focus on factors aiding children with asthma to getting better over the years.

The aim of this study was to analyze possible factors related to the outcome in an Asthma diagnosis reassessment by parental questionnaire at the age of ten of the children earlier having been identified with a hospital or primary health care diagnosis of asthma at least once between 0-7 years of age in a total birth-year cohort in a defined Swedish geographical area.

\section{Methods}

\section{Study design}

A birth cohort of all children born 1990 (total $\mathrm{N}=$ 2104 children) from a defined Swedish region (County Council of Östergötland) with 150000 inhabitants (of which about 125000 urban), born at the University Hospital in Linköping (which is the only somatic hospital in the region and where all births occurred), except those suffering neonatal death and those living outside the region, were included in the study. At the age of seven, all of them still living in the region were included in a follow-up of their computerised medical records, which were examined for the occurrence of the diagnosis asthma (ICD-9:493) at the Department of Paediatrics at the University Hospital and at all 14 PHC Units and at the private Paediatricians in the region. Of the initial total birth cohort, 82 $\%$ ( $n=1752$ children) were still living in the region at the age of seven. Children born in 1990 that had moved into the study-area after 1990 were not included in the study (17).

Data of perinatal and obstetric factors as well as some social factors at baseline (1990) were obtained by investigations of the maternal medical records at the University Hospital, including PHC data of the statements made by the mid-wife in her records of the check-up of the mothers during the pregnancy (17). In the follow-up at the age of seven, $n=191$ children of the defined remaining birth cohort were found with a documented asthma diagnosis at one or more occasions over the 0-7-year interval in the medical records $(18,19)$.

A further data collection was made through a manual scrutiny by one of us (E.R.) of all asthma-relevant medical records at the Department of Paediatrics at the University Hospital for all of the $\mathrm{n}=63$ children in the NA group. This follow-up analysis mainly focused on diagnosis setting, possible differential diagnoses, number of visits and medical treatment given to these children up to the age of ten.

\section{Subjects}

At the age of 10 the parents of these $n=191$ children with a documented asthma diagnosis, were sent the International Study of Asthma and Allergies in Childhood (ISAAC) questionnaire $(20,21)$ concerning asthma history, symptoms, heredity, socio-economic factors and environmental exposure. The response 
rate to this postal questionnaire was $83 \%(n=159)$. Only in $60.4 \%$ of them $(n=96)$, the parents confirmed that their child ever had asthma, whereas in $39.6 \%$ $(n=63)$ they answered "No" to this question. These two groups, labelled A (confirmed asthma diagnosis at the age of 10) and NA (negated asthma diagnosis at the age of 10), are further analysed in the present paper. A flow chart of the eligible children and those participating is presented in figure 1.

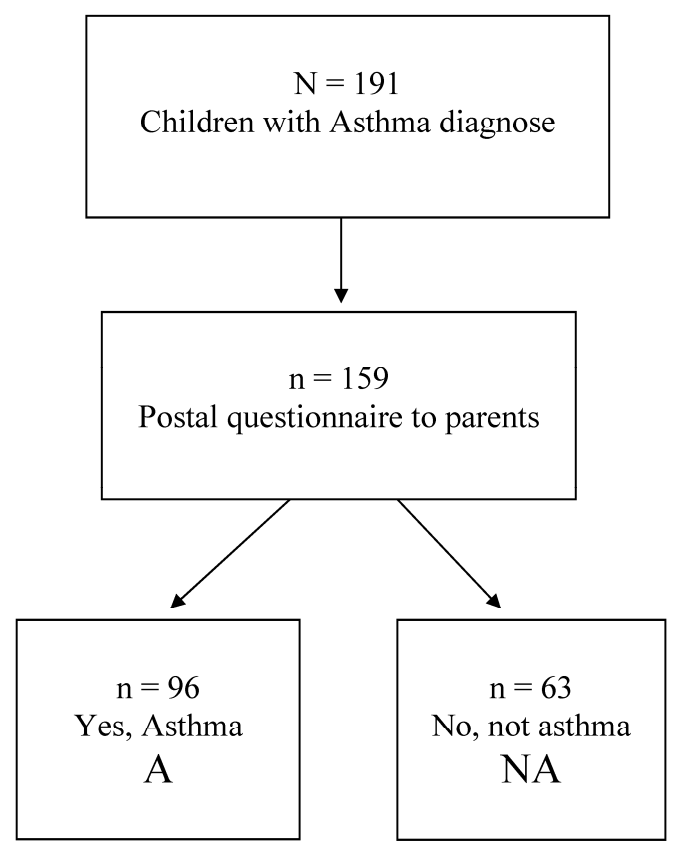

Figure I: Flow chart of the eligible children in the study.

\section{Statistics}

All data were stored in a common database and statistically analysed using the SPSS version 14.0 programme (SPSS Inc., Chicago, IL, USA). Significance of differences was assessed by the Chi ${ }^{2}$-method for categorical variables and for continuous variables by Spearman's non-parametric correlation and the 2-sided ANOVA-test. Odds ratios and $95 \%$ confidence intervals were also calculated and a p-value of less than $\mathrm{p}<0.05$ was considered statistically significant.

A multiple logistic regression analysis was made to determine the independent variables that positively might affect the chance of not reporting asthma at the age of 10. Prior to this analysis a correlation matrix was initially made for all independent variables in order to determine which indicators to be included in the final model. For those variables that were inter-correlated and represented the same factor, only those which were most strongly statistically correlated to the dependent variable (i.e. reporting asthma or not reporting asthma at the age of 10) and least highly inter-correlated, were included in the final multiple logistic regression model. Odds ratios and 95\% confidence intervals were estimated for variables included in the multivariate logistic regression analysis.

\section{Ethical approval}

The study was approved 1996 (Dnr. 96-164) by the Ethical Committee at the Faculty of Health Sciences, Linköpings Universitet, Sweden.

\section{Results}

Of the previously well documented children with asthma diagnosis $(n=159)$, the parents to $39.6 \%$ of them $(n=63)$ reported in the ISAAC questionnaire at the age of ten that their child never had asthma (group NA), while $60.4 \%(n=96)$ confirmed their children's asthma diagnosis (group A). The proportion of boys and girls in the two groups were quite similar $(p=0.866)$ as shown in table 1 . There were no differences in having younger or older siblings in the groups. A slight difference was seen between the two groups concerning socio-economic factors in which the proportion of blue collar fathers and mothers tended to be a bit higher in group A than group NA. The number of children living in a villa rather than an apartment was however significantly higher $(p=0.005)$ at the age of ten in group NA than in group $\mathbf{A}$. This proportion increased from $68.3 \%$ at the age of three to $87.3 \%$ at the age of ten for group NA, and from $62.5 \%$ at the age of three to 66.7 at the age of ten for children in group A. The proportion of children living in urban areas tended to be higher in group NA than in group A both at the age of three and at the age of ten.

Different residential and environmental exposures in the groups are shown in table 2. Exposure to smoking in the family tended to be slightly higher in group NA than in group A. Present or previous exposure to pet allergens in the family tended to be higher in group NA for cat and dog and significantly higher $(p=0.008)$ concerning exposure for other animals with furs. Also horse riding of the child or by other members in the family tended to be higher in group NA than in group A. Present or previous residential environmental exposure like; reports of mould damage, unusual or bad smell or dry air inside the house were significantly more frequent reported in group A than in group NA. 
Table I: Social and demographic factors among $N=159$ children confirming (group A) respective neglecting their asthma diagnosis (group NA) at the age of 10.

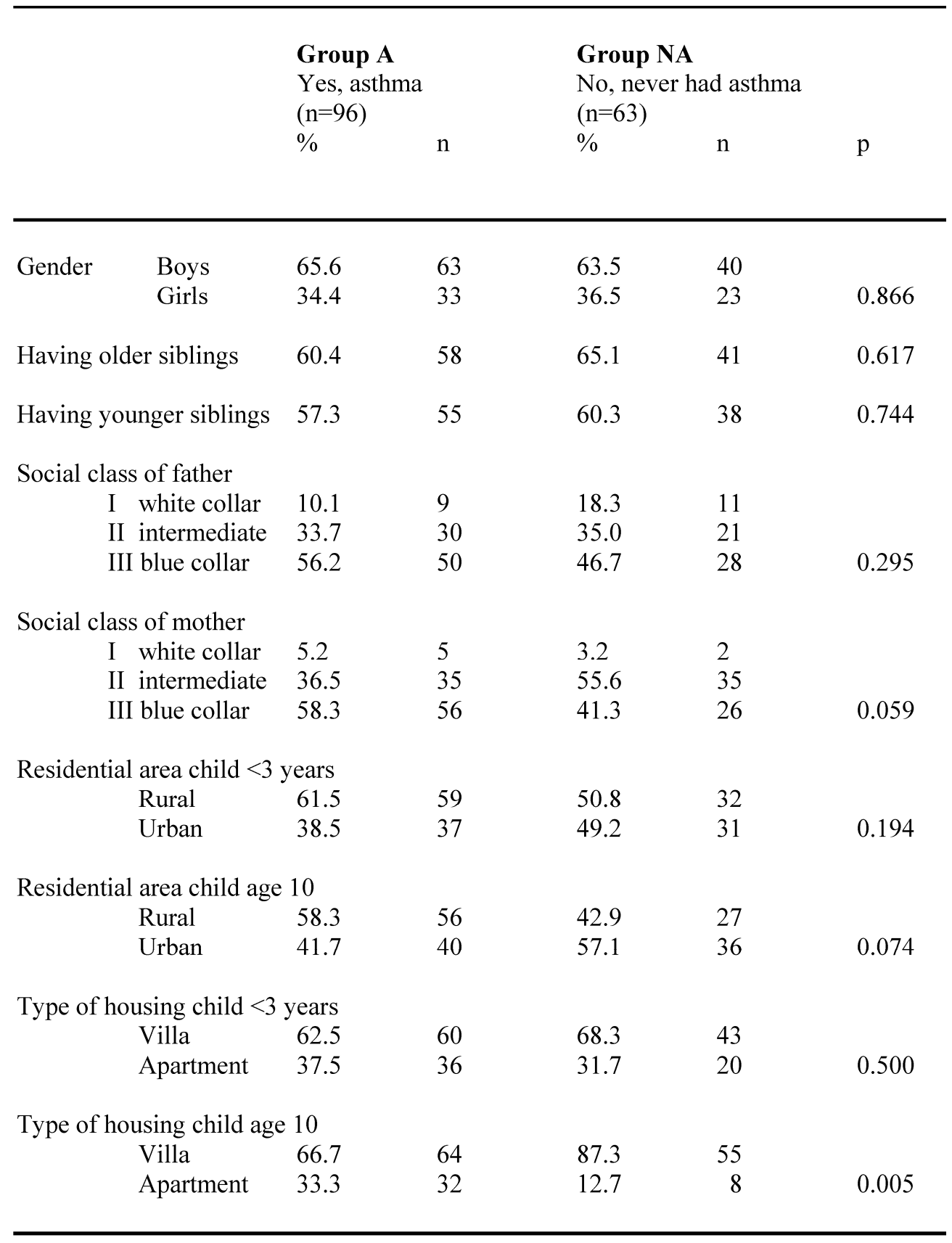


Table 2: Residential and environmental exposure among children $(N=159)$ confirming (group $A)$ respective neglecting (group NA) their asthma diagnosis at the age of 10.

\section{Group A Group NA}

Yes, asthma No, never had asthma

$\mathrm{n}=96 \quad \mathrm{n}=63$

$\% \quad \mathrm{n} \quad \% \quad \mathrm{n} \quad \mathrm{p}$

Exposure to smoking in the family: Smoking at home child's first year Father smoker child age 10

Mother smoker child age 10
16.716

19.818

33.332
22.214

27.917

34.922
0.381

0.246

0.836

Exposure to pet allergens (present or previous) in the family:

\begin{tabular}{|c|c|c|c|}
\hline Cat & & & \\
\hline Dog & $17.7 \quad 17$ & 28.618 & 0.106 \\
\hline Other animals with furs & 34.433 & 55.635 & 0.008 \\
\hline Cage-birds & 16.716 & 9.56 & 0.202 \\
\hline Child horse riding & $22.9 \quad 22$ & 38.124 & 0.039 \\
\hline $\begin{array}{l}\text { Other family member horse } \\
\text { riding }\end{array}$ & 33.332 & 38.124 & 0.539 \\
\hline \multicolumn{4}{|c|}{ Residential exposure (present or previous): } \\
\hline Reports of mould damage & 36.535 & 15.910 & 0.005 \\
\hline Reports of unusual or bad smell & 22.922 & 9.56 & 0.030 \\
\hline $\begin{array}{l}\text { Reports of mist on the } \\
\text { inside of window }\end{array}$ & 34.433 & 25.416 & 0.230 \\
\hline $\begin{array}{l}\text { Reports of dry air } \\
\text { inside the house }\end{array}$ & 28.127 & 14.39 & 0.041 \\
\hline
\end{tabular}

There was no difference $(p=0.412)$ in the mean birth weight of children in group A: 3387.3 grams (+650.2 gr) compared to the children in group NA: 3 475.3 grams (+-673.5 gr). Neither were there any statistical significant differences between the two groups concerning the perinatal and obstetric factors measured, like age of mother at delivery, first time pregnancy, and gestational week, time between labour and birth or possible events of complications at delivery.

Reports of heredity for asthma and allergy among children confirming (group A) respective negating (group NA) their asthma diagnosis are shown in table 3. Heredity for asthma and allergy in the family at child birth as well as reported asthma, allergic rhinitis and eczema in the family when the child was ten years old, were all significantly more frequent among group A than group NA. However, also a substantial fraction of the children in group NA reported heredity for these diseases.

Figure 2 shows the number of registered health care visits with a diagnosis of asthma from birth up to the age of seven for the children in group $\mathbf{A}$ and group NA. The NA group had significantly $(p<0.0001)$ fewer health care visits than group $\mathbf{A}$. The mean age when the asthma diagnosis was set was significantly lower $(p=0.001)$ in the children in group NA than in group A, as shown in figure 3 . However, there was no significant difference $(p=0.385)$ between the two groups whether the asthma diagnosis was set at the University Hospital or in PHC. The asthma diagnosis was set at the Paediatric clinic at the University Hospital for $91.4 \%$ of the children in group A and for $95.1 \%$ of the children in group NA, the others were diagnosed in PHC. 


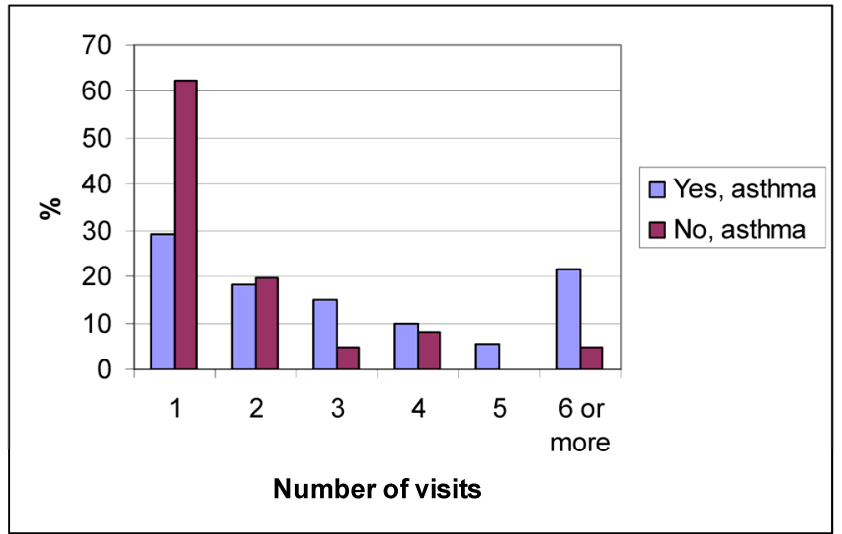

Figure 2: Number of health care visits of the children confirming respective neglecting their asthma diagnosis.

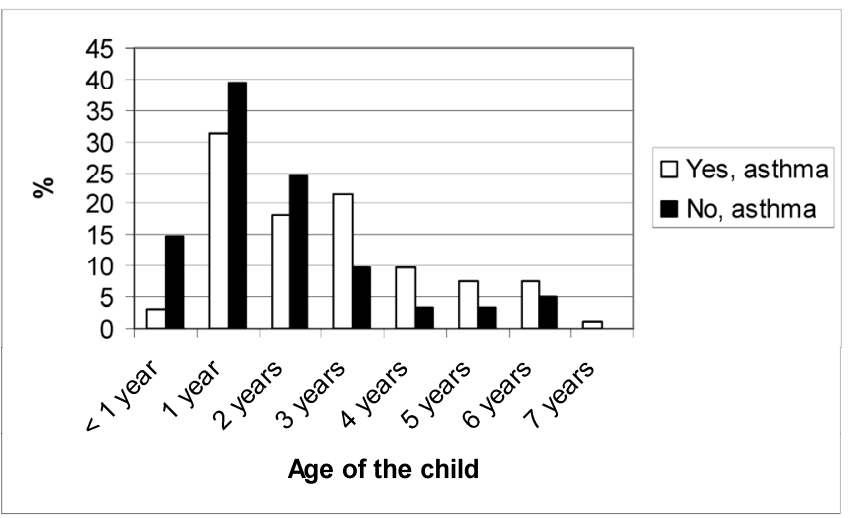

Figure 3: Age when asthma diagnoses were set for the children confirming respective neglecting their asthma diagnosis.

Table 3: Reported hereditary of asthma and allergy among children confirming (group A) respective neglecting (group NA) their asthma diagnosis at the age of 10.

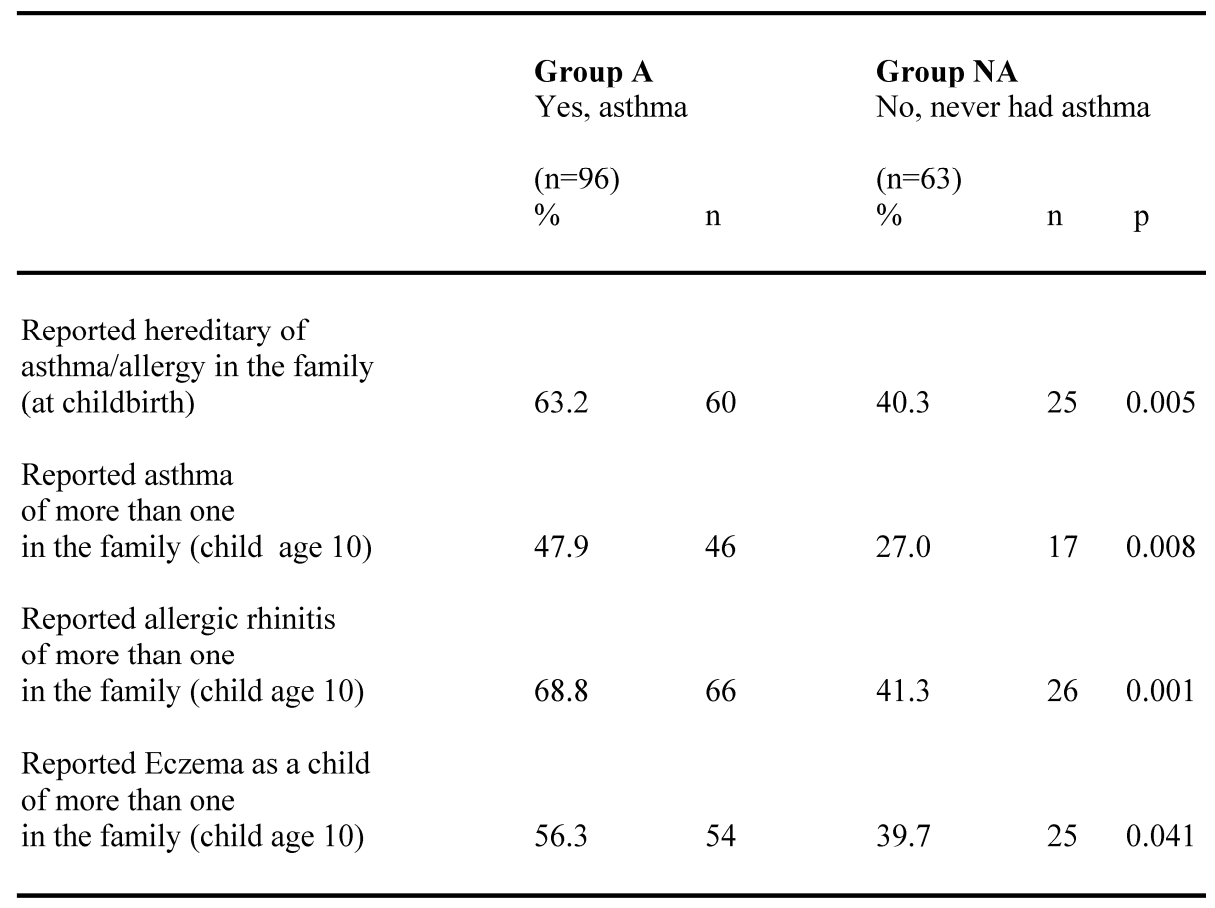

Perceived symptoms and allergic co-morbidity for the two groups are compared in table 4 . Almost all children $(92.7 \%)$ in group A reported occurrence of wheezing or whistling in the chest at any time in the past, which is significantly higher $(p<0.0001)$ than in group NA, where $44.4 \%$ reported this. All other described asthma symptoms were likewise significantly more frequently reported in group $\mathbf{A}$ than in group
NA, where only a few children reported such symptoms. Allergic symptoms like problems with sneezing or a runny and blocked nose without a cold or a flu were reported in about $60 \%$ in group A, significantly higher $(p<0.0001)$ than in group NA, were about $20 \%$ reported these symptoms. Reports of hay fewer, itchy rash and eczema were also significantly more frequent among group A than group NA. 
Table 4: Perceived symptoms and allergic co-morbidity reported by the parents at the age of 10 for children confirming (group A) respective neglecting (group NA) their asthma diagnosis.

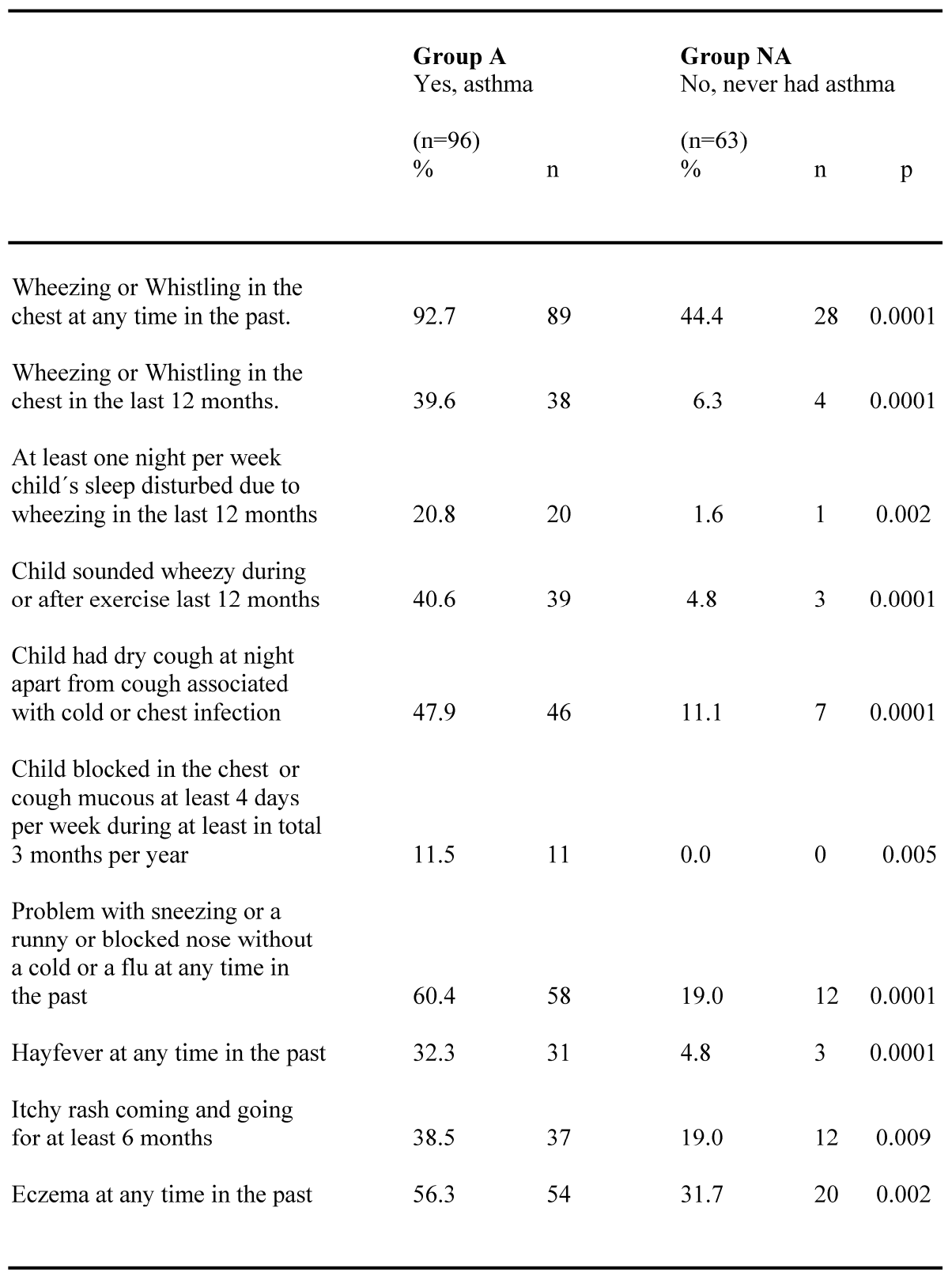

A multiple logistic regression analysis was made to determine the independent variables that positively might affect the chance of not reporting asthma at the age of 10 , and is shown in table 5 . It revealed four significant and independent factors associated to this chance, namely, not having any previous experiences of allergic symptoms in the past $(p<0.0001)$, only having one or two visits at the hospital for asthma diagnosis in the 0-7 interval $(\mathrm{p}=0.001)$, not living in a flat but a villa at the age of ten $(\mathrm{p}=0.029)$ and no previous perception of mist or mould damage in the house $(p=0.052)$. If no heredity of asthma in the family was documented and if the child actually had ex- perienced exposure to animals with furs (excluding cats and dogs) when growing up, an increased, but not significant, chance of not reporting asthma at the age of ten was also indicated.

A renewed analysis of the medical records in the NA group by one of us (E.R.) fully confirmed the initial asthma diagnosis in $44.4 \%$, partially in $42.9 \%$, whereas in $12.7 \%$ other disorders like respiratory anomalies or prematurity were concluded. When the asthma diagnosis was first set for these children, 77\% were prescribed pharmaceuticals for asthma symptoms, while the rest of them, $23 \%$, did not get any medication. 
Table 5. Multiple logistic analyses of different factors affecting the possibility that children with a documented asthma diagnose should report that they at the age of 10 should report no asthma.

\begin{tabular}{|c|c|c|c|c|}
\hline & $\mathrm{n}$ & OR & $95 \% \mathrm{CI}$ & p-value \\
\hline $\begin{array}{l}\text { No symptoms of sneezing, } \\
\text { runny or blocked nose } \\
\text { without a cold or flu in the past }\end{array}$ & 87 & 5.11 & $2.19-11.94$ & $<0.0001$ \\
\hline $\begin{array}{l}\text { Few visits (1-2) at hospital with } \\
\text { asthma diagnosis }\end{array}$ & 94 & 4.28 & $1.75-10.45$ & 0.001 \\
\hline Living in a villa at the age of 10 & 116 & 3.06 & $1.12-8.36$ & 0.029 \\
\hline $\begin{array}{l}\text { No perception of mist or mould } \\
\text { damage in the house }\end{array}$ & 110 & 2.56 & $1.00-6.60$ & 0.052 \\
\hline No heredity of asthma in the family & 94 & 1.74 & $0.74-4.08$ & 0.203 \\
\hline $\begin{array}{l}\text { Having animals with furs in the house } \\
\text { (except cat or dog) }\end{array}$ & 65 & 1.42 & $0.61-4.28$ & 0.418 \\
\hline
\end{tabular}

(Multiple logistic regression model Chi-square $=55.53, \mathrm{df}=6 \mathrm{p}<0.0001$ )

\section{Discussion}

This study is an inventory of hospital and PHC-diagnosed childhood asthma in a sizeable whole birth-year cohort from a defined affluent geographical area and followed up to the age of 7 and 10 years. The study includes medical record examination and a 'spectral analysis' in remaining and non-remaining cases at the age of ten of asthma symptoms, signs and associated heredity, environmental risk exposition as well as possible salutogenetic factors. The present report focuses upon these, and in particular the salutogenetic aspects: How comes, that in a parental recall, almost $40 \%$ of the children with a medically confirmed cumulative asthma diagnosis up to the age of seven, at the age of ten were reported to never have had asthma?

The analysis was directed towards possible salutogenetic factors aiding children with asthma to recover or improve over the years. The multiple logistic analyses revealed four significant and independent factors associated with this event. They were; Not having any major allergic symptoms in the past $(p<0.0001)$, only having one or two visits at the hospital for asthma diagnosis as a child $(p=0.001)$, not living in a flat but a villa at the age of ten $(\mathrm{p}=0.029)$, and no previous perception of mist or mould damage in the house $(p=0.052)$. In the single risk factor analyses, marked co-varying differences were likewise seen between the $\mathbf{A}$ and NA groups in terms of much higher rate of asthma-related and allergic symptoms, signs and associations in the former. The frequencies in the NA group were quite similar with frequencies previous reported for a non-asthma control sub sample to this cohort (19). Interestingly, the exposition for pet animals tended to be higher in the NA cases, which may support the hygiene hypothesis, but may also be due to higher sensitivity in the $\mathbf{A}$ group.

Previous studies have shown that also parentally completed ISAAC-based questionnaire provides an acceptable estimation of the prevalence of asthma in children 2-6 years of age, although no more than about half of the individual patients identified in this manner are the same as those identified clinically. In a study of children between $1-2$ years of age the parental questionnaire was only able to identify $54 \%$ of the children with a medical record of asthma (25). Even in our investigation there seems to be a similar low concordance when comparisons are made of the occurrence of clinically diagnosed asthma with parental assessment in the ISAAC questionnaire, especially apparent for the youngest children. Thus it was mainly in the children whose first and often single or just once repeated clinical asthma diagnosis was set in the early postnatal up to three years' age period, that their parents negated their ever having had asthma.

\section{Study limitations}

An implication of our findings regards the quality of the information given to the parents when the 
clinical asthma diagnosis was made. There might be a recall bias, but there might also be a deficiency of the primary information as well as the parental informed consent. In any case, such findings corroborate the data quality even though there also exist obvious limitations. The worldwide established ISAAC questionnaire, based on self-reported data and used in this study, is judged to be a well validated instrument for the determinations of asthma symptoms $(22,23)$. However, when using such data one needs to consider the possibilities of recall-bias among the respondents. But in general, self-reports are reliable and well established (24).

Almost all diagnoses were made at the paediatric clinic at the University hospital and only a small fraction, $5 \%$ at primary care. However, the successively amended regional quality program for asthma diagnosis is nowadays shared, but was more lax 15 years ago than today, which introduces a possible bias since many of the NA cases were early diagnosed. Yet, there are balancing trends as well, among which both the professional skills, the expanding diagnostic arsenal and, not the least, a new range of pharmaceuticals are notable, leaving us with a set of established diagnosis as the dependant data of the study. However, according to current classification (26), some of the NA cases would today be regarded as transient early wheezing, which is a benign condition, not associated with subsequent wheeze or risk for asthma (9).

\section{Conclusions}

In conclusion, one cannot neglect the possibility of true improvement and cure, however, under the influence of genuine salutogenetic factors, of which upward social mobility i.e. moving to better social circumstances and housing might be one as judged from the multiple logistic analysis. However, then coming from initially poorer conditions, and also the observation of increased exposure to pet animals in the NA group may support the 'hygiene hypothesis'. An active, vital life style and improvement of the social and socioeconomic situation point at the pivotal role of information and education for a better health. As a result this also leads to fewer health care visits for childhood asthma, not least in primary health care. But constitutional factors are plausibly of great importance. In the early postnatal stage, obstructive and bronchospastic symptoms typical of asthma may be unspecific, and those cases not continuing to persisting disease tend to have identifiable salutogenetic factors of constitutional rather than environmental nature, namely, an overall reduced allergic predisposition. One must also remember that the problem with small airways will anatomically be reduced over time when the child grows up and the airways widen. An implication for primary care as well as hospital care from this study is not to underestimate the importance of good communication between the patient and the care-giver.

\section{Conflict of Interest}

The authors have declared that no conflict of interest exists.

\section{References}

1. Danov Z, Guilbert TW. Prevention of asthma in childhood. Curr Opin Allergy Clin Immunol. 2007; 7: 174-9.

2. Luri N, Bauer EJ, Brady C. Asthma outcomes at an inner-city school-based health center. J Sch Health. 2001; 71: 9-16.

3. Krieger JW, Song L, Takaro TK, Stout J. Asthma and the home environment of low-income urban children: preliminary findings from the Seattle-King County healthy homes project. J Urban Health. 2000; 77: 50-67.

4. Pearce N, Douwes J. The global epidemiology of asthma in children. Int J Tuberc Lung Dis. 2006; 10: 125-32.

5. Arruda LK, Sole D, Baena-Cagnani CE, Naspitz CK. Risk factors for asthma and atopy. Curr Opin Allergy Clin Immunol. 2005; 5: 153-9.

6. Björksten B. Evidence of probiotics in prevention of allergy and asthma. Curr Drug Targets Inflamm Allergy. 2005; 4: 599-604.

7. Platt-Mills TA, Erwin E, Heymann P, Woodfolk J. Is the hygiene hypothesis still a viable explanation for the increased prevalence of asthma? Allergy. 2005; 60 (Suppl 79): 25-31.

8. Maziak W. The asthma epidemic and our artificial habitats. BMC Pulm Med. 2005; 5: 5.

9. Wright AL. Epidemiology of asthma and recurrent wheeze in childhood. Clin Rev Allergy Immunol. 2002; 22: 33-44.

10. Strachan D, Gerritsen J. Long-term outcome of early childhood wheezing: population data. Eur Respir J. 1996; 21: 42s-47s.

11. Sears MR, Greene JM, Willan AR, Wiecek EM, Taylor DR, Flannery EM, Cowan JO, Herbison GP, Silvia PA, Poulton R. A longitudinal, population-based, cohort study of childhood asthma followed to adulthood. N Engl J Med. 2003; 349: 1414-22.

12. Van den Toorn LM, Overbeek SE, Prins JB, Hoogsteden HC, de Jongste JC. Asthma remission: does it exist? Curr Opin Pulm Med. 2003; 9: 15-20.

13. Roorda RJ. Prognostic factors for the outcome of childhood asthma in adolescence. Thorax. 1996; 51 (Suppl 1): S7-12.

14. Rothman, K. Modern Epidemiology. Boston/Toronto: Little Brown and Company 1986.

15. Langius A, Björvell $\mathrm{H}$, Antonowsky A. The sense of coherence concept and its relation to personality traits in Swedish samples. Scand J Caring Sci. 1992; 6: 165-71.

16. Antonovsky, A. The moral and the healthy: identical, overlapping or orthogonal? Isr J Psychiatry Relat Sci. 1995; 32: 5-13.

17. Roel E, Olsen-Faresjö A, Kjellman M N-I, Faresjö T. Cumulative incidence of asthma diagnosis at the age of seven in a birth cohort. Eur J Gen Pract. 1999; 5: 71-74.

18. Roel E, Olsen-Faresjö Å, Zetterström O, Faresjö T. Perinatal, social and environmental factors and the risk for childhood asthma in a 10-year follow-up. Pediatr Asthma Allergy Immunol. 2004; 17: 136-145.

19. Roel E, Faresjö Å, Zetterström O, Trell E, Faresjö T. Clinically diagnosed childhood asthma and follow-up of symptoms in a Swedish case control study. BMC Fam Pract. 2005; 6: 16. 
20. Keil U, Weilnad SK, Duhme H, Chambless L. The international Study of Asthma and Allergies in Childhood (ISAAC): objectives and methods; results from german ISAAC centres concerning traffic density and wheezing and allergic rhinitis. Toxicol Lett. 1996; 86: 99-103.

21. Asher I. ISAAC International Study of Asthma and Allergies in Childhood. Pediatr Pulmonol. 2007; 42:100.

22. Jenkins MA, Clarke JR, Carlin JB, Robertson CF, Hopper JL, Dalton MF, Holst DP, Choi K, Giles GG. Validation of questionnaire and bronchial hyperresponsiveness against respiratory physician assessment in the diagnosis of asthma. Int J Epidemiol. 1996; 25: 609-16.

23. Pearce N, Sunyer J, Cheng S, Chinn S, Björksten B, Burr M, Keil $\mathrm{U}$, Anderson HR, Burney P. Comparison of asthma prevalence in the ISAAC and the ECRHS. ISAAC Steering Committee and the European Community Respiratory Health Survey. International Study of Asthma and Allergies in Childhood. Eur Respir J. 2000; 16: 420-6.

24. Kurland LT, Molgaard CA. The patient record in epidemiology. Sci Am. 1981; 245: 46-55.

25. Hederos CA, Hasselgren M, Hedlin G, Bornehag CG. Comparison of clinically diagnosed asthma with parental assessment of children's asthma in a questionnaire. Pediatr Allergy Immunol. 2007; 18: 135-41.

26. Sterling YM, El-Dahr JM. Wheezing and asthma in early childhood: an update. Pediatr Nurs. 2006; 32: 27-31. 